\title{
Trade-Offs: Pros and Cons of Being a Doctor and Patient in Canada
}

\author{
Peter Cram, MD MBA ${ }^{1,2}$, Irfan Dhalla, MD MSc $2,3,4$, and Janice L. Kwan, MD MPH ${ }^{1,2}$ \\ 'Division of General Internal Medicine and Geriatrics, Sinai Health System and University Health Network, Toronto, ON, Canada; ${ }^{2}$ Faculty of \\ Medicine, University of Toronto, Toronto, ON, Canada; ${ }^{3}$ Institute for Health Policy, Management, and Evaluation, University of Toronto, Toronto, ON, \\ Canada; ${ }^{4}$ Division of General Internal Medicine, St. Michael's Hospital, Toronto, ON, Canada.
}

KEY WORDS: Canada; international comparison; health insurance; cost sharing; access.

J Gen Intern Med 32(5):563-5

DOI: $10.1007 / \mathrm{s} 11606-016-3874-0$

(C) Society of General Internal Medicine 2016

W e will begin with a modest question.

What are you willing to sacrifice for sustainable universal health insurance coverage? ${ }^{1}$ Higher taxes? What about losing rapid access to non-emergency endoscopy, MRI, and subspecialist consultation? What about having your mother wait 6 months for her hip replacement $(40 \%$ of procedures in British Columbia and $13 \%$ in Alberta exceeded this threshold in 2015)? $?^{2}$ Or having your father-in-law spend $24 \mathrm{~h}$ waiting in an emergency department corridor for an inpatient bed to become available upstairs, only to be moved to an overflow cot in a bustling ward hallway for his 3-day hospital stay?

These downsides are real, and we (a US citizen now living in Canada [PC] and two lifelong Canadians [ID and JLK]) feel them when we pay higher taxes, wait for care for our loved ones, and face delays in providing care to our patients. But the upsides are also real and, from our perspective, worth the sacrifices.

The upsides include fewer billing requirements (despite using ICD-10), because we have a single payer and reduced clinical documentation requirements. We don't have the angst of wondering if our patients or family members will lose their health insurance if they lose their job or develop a chronic illness. And while income taxes are high in Canada-approximately $50 \%$ for the highest earners - provincial health plans have no deductibles for physician and hospital care, though public coverage for outpatient medications is patchy. Interestingly, Tommy Douglas, generally considered the father of Canadian universal healthcare, says that the absence of even a nominal co-payment model could weaken the public's appreciation of the true value of universal healthcare. ${ }^{3}$ But an absence of cost sharing does have some benefits, particularly for patients with lower incomes or multiple chronic conditions, where even modest copays can become barriers to care. ${ }^{4}$

Published online October 4, 2016
We all know the numbers. The United States spends about $\$ 1.00$ on healthcare for every $\$ 0.60$ spent by other developed countries with roughly similar per capita income (Canada, United Kingdom, Germany). ${ }^{5}$ The $67 \%$ additional spending in the US is often is portrayed simplistically as waste: excess testing and procedures, administrative costs for unnecessary bureaucracy, and profiteering by hospital and insurance industry executives.

This is not entirely true. The extra spending buys some good stuff: for example, more sophisticated electronic health records (EHRs) and timelier access to stem cell transplants. ${ }^{6,7}$

But...Americans do not get $67 \%$ better health, or even $67 \%$ better healthcare. Americans do not live longer and do not score higher on other measures of well-being than Canadians, Britons, or Germans. ${ }^{8}$

Phrased differently, the publicly funded Canadian system has some major advantages over the patchwork of public and private insurance in the US. However, we in Canada also have some significant problems, as noted by scholars including former University of Toronto President David Naylor, Allan Detsky, and Uwe Reinhardt. ${ }^{9,10}$

In the next few paragraphs we will address some of the nuances of Canadian healthcare using several dimensions of quality chosen by the US Institute of Medicine. ${ }^{11}$

1) Efficiency: In the US, fee-for-service reimbursement simultaneously incentivizes both excess utilization and efficiency. Excessive utilization is encouraged, because each additional admission, clinic visit, or diagnostic test generates additional payments to physicians, with no effective shut-off valve. ${ }^{12,13}$ At the same time, innovations like diagnosis-related group (DRG)-based reimbursement for acute care and episode-of-care payments incentivize hospitals to reduce waste, because prolonged hospital stays and excessive testing erode hospital profits. Historically, although the US has been highly efficient on certain measures of "throughput," like hospital length of stay, excess utilization has largely overshadowed efficiency in US healthcare. ${ }^{14,15}$

In Canada, efficiency in certain areas is excellent, imposed by provincial funding models. Inpatient beds, operating room time, and imaging 
availability are rationed and scarce. Physicians are left to prioritize which patients require costly tests and treatments and which do not. Efficiency, as measured by sustainable levels of per capita utilization of procedures, is high. Unfortunately, efficiency as measured by length of stay is impeded by constraints in the availability of imaging tests, endoscopy, and operating room slots. Likewise, provinces limit the supply of post-acute care, so patients often wait in-hospital for long-term care. There is even a Canadian designation for inpatients who remain in the hospital for weeks or even months while acute care hospitals search for suitable long-term-care: "alternative level of care" [ALC] patients (the UK equivalent is "bed blockers").

2) Timely access: Timely access to care in Canada is a significant problem across the country. ${ }^{16}$ While international comparisons are fraught with methodological concerns, Canada has fewer physicians and inpatient beds per 1000 population (2.5 and 1.8) than most other OECD [Organisation for Economic Co-operation and Development] countries, including the US (2.6 and 2.7), UK (2.7 and 2.7), and Germany (4.1 and 5.7). ${ }^{5}$ Only $37 \%$ of Canadians report that they can get an appointment with their primary care physician within $48 \mathrm{~h}$, and data from primary care physicians themselves similarly suggest timely access is not good when compared to other OECD countries. ${ }^{17,18}$ Family doctors are the backbone of the Canadian healthcare system, providing virtually all primary care; they also serve as the gatekeepers for accessing specialty care. Many family doctors have very small practices, such that only $48 \%$ of family doctors report after-hours coverage for their practice without resorting to the emergency department. ${ }^{17}$

As a result, many Canadians are forced to seek care in overtaxed emergency departments, where wait times can be excessive; crowding has been associated with delays in treatment of conditions ranging from asthma to myocardial infarction. ${ }^{19}$ Access is also problematic for patients needing to see specialists ranging from geriatricians to psychiatrists to neurologists, though links between prolonged wait times and worse patient outcomes are quite limited. ${ }^{20,21}$ Canadian patients are known to partake in medical tourism to obtain services that cannot be obtained locally, ${ }^{22,23}$ though precise estimates of overseas travel are uncertain. ${ }^{24}$ It is also important to note that a culture of "workarounds" has developed, whereby most industrious clinicians have ways to assist their patients in getting the care they need. But the system is far more difficult than it needs to be. I (PC) sometimes wonder whether my colleagues or family in the
US would accept waits for non-life-threatening care if it were a precondition for universal insurance coverage.

3) Equity: In many ways, our different healthcare systems reflect the different values of our countries. The Canadian system prioritizes community; the US prioritizes competition and autonomy. A limited body of empirical research suggests greater equity and smaller disparities in Canada. For example, new immigrants to Canada have less of a healthcare disadvantage than immigrants to the US. ${ }^{25}$ Likewise, there is evidence of improved breast cancer survival for lower-income Canadians compared to Americans, ${ }^{26}$ again potentially reflecting the benefits of universal insurance.

4) Patient centered: mIf there were one area where we might fault the Canadian system, it would be patientcenteredness. International comparisons of patient experience are extremely complex, reflecting both random and non-random (i.e., cultural, societal) differences in how certain populations view healthcare delivery. ${ }^{27}$ What instruments should we use? How do we account for differences in socioeconomic status, health insurance coverage, or deeply ingrained cultural differences between the two countries?

Nevertheless, structural issues play an important role. In the US, hospitals compete for patients. The undesirable effects of hospital competition in the US are well recognized, ${ }^{28}$ but the benefits are too often ignored. Hospitals invest in comfortable birthing suites and welcoming waiting rooms, and train staff to treat patients and families nicely. ${ }^{29}$ Hospitals, physicians, and all members of inter-professional teams have a strong incentive to provide both good outcomes and good patient experience.

Contrast this with Canada, where care is generally provided free of charge, but hospitals, as part of the public sector, act more like the postal service, tax collector, or the muchmaligned department of motor vehicles than like restaurants or hotels. While there is hope that Canadian healthcare can adopt the best practices of large government-run healthcare systems, including the US Veterans Administration, ${ }^{30,31}$ recent scandals and setbacks within the VA are a reminder that the road is not easy, nor success guaranteed. Recognizing the potential benefits of small doses of competition, there are periodic calls for the creation of a parallel private system in Canada to motivate improvements. ${ }^{32}$ So far, tangible progress has been negligible, with the exception of modest funding reform efforts in some provinces. ${ }^{33}$ Furthermore, there is concern that a two-tier system will undermine the country's commitment to healthcare equity. ${ }^{32}$

In sum, Canada's public healthcare system provides more equitable care, a more robust safety net (particularly for those in the bottom half of the income scale), and a level of comfort for everybody (including many of the wealthy) that illness will 
not lead to bankruptcy. At the same time, many persons will pay more taxes, wait longer, and receive less patient-centered care than they are accustomed to.

Tradeoffs we strongly accept, but tradeoffs nonetheless.

Acknowledgments: ID receives funding from Health Quality Ontario, a governmental advisory agency. The opinions expressed in this publication do not necessarily represent the opinions of Health Quality Ontario. No endorsement is intended or should be inferred. $P C$ is supported in part by a K24 (AR062133) award from the National Institute of Arthritis and Musculoskeletal and Skin Diseases (NIAMS) at the National Institutes of Health (NIH).

Corresponding Author: Peter Cram, MD MBA; Division of General Internal Medicine and GeriatricsSinai Health System and University Health Network, Toronto, ON, Canada (e-mail: peter.cram@uhn.ca).

\section{Compliance with Ethical Standards:}

Conflict of Interest: The authors declare that they do not have a conflict of interest.

\section{REFERENCES}

1. Dhalla I. Canada's health care system and the sustainability paradox. CMAJ. 2007; 177:51-3.

2. 2015 Wait Times. at Available at: http://waittimes.cihi.ca/. Accessed Sept 92016.

3. Simpson J. Chronic condition. Toronto: Allan Lane; 2012.

4. Sinnott SJ, Buckley C, O'Riordan D, Bradley C, whelton H. The effect of copayments for prescriptions on adherence to prescription medicines in publicly insured populations, a systematic review and meta-analysis. PLoS One. 2013;8.

5. Squires D, Anderson C. U.S. health care from a global perspective: spending, use of services, prices, and health in 13 countries. Issue Brief (Commonw Fund). 2015;15:1-15.

6. Collier R. National physician survey: EMR use at 75\%. CMAJ. 2015;187:E17-8.

7. Zlomislic D. Top doctors, health critics blast health minister Eric Hoskins for stem cell transplant crisis. Toronto Star; 2016.

8. Veenhoven R. Cross-national differences in happiness: cultural measurement bias or effect of culture? Int J Wellbeing. 2012;2:333-53.

9. Detsky AS, Naylor CD. Canada's health care system-reform delayed. N Engl J Med. 2003;349:804-10.

10. Anderson GF, Reinhardt UE, Hussey PS, Petrosyan V. It's the prices, stupid: why the United States is so different from other countries. Health Aff (Millwood). 2003;22:89-105.

11. Institute of Medicine, Committee on Quality Health Care in America. Crossing the quality chasm: a new health system for the 21 st century. Washington, D.C.: National Academy Press; 2001.

12. Merx $\mathbf{H}$, Dreinhofer $\mathbf{K}$, Schrader $\mathbf{P}$, et al. International variation in hip replacement rates. Ann Rheum Dis. 2003;62:222-6.
13. Ko DT, Tu JV, Austin PC, et al. Prevalence and extent of obstructive coronary artery disease among patients undergoing elective coronary catheterization in New York State and Ontario. JAMA. 2013;310:163-9.

14. Medin E, Goude F, Melberg HO, Tediosi F, Belicza E, Peltola M. European regional differences in All-cause mortality and length of stay for patients with hip fracture. Health Econ. 2015;24(Suppl 2):53-64.

15. Miller BJ, Cai X, Cram P. Mortality rates are similar after hip fractures for rural and urban patients. Clin Orthop Relat Res. 2011.

16. Mathews M, Seguin M, Chowdhury N, Card RT. A qualitative study of factors influencing different generations of Newfoundland and Saskatchewan trained physicians to leave a work location. Hum Resour Health. 2012;10:18.

17. Canadian Institute for Health Information. How Canada compares: results from the commonwealth fund 2015 International Health Policy Survey of Primary Care Physicians; 2016.

18. The Commonwealth Fund. The commonwealth fund 2012 international health policy survey of primary care physicians; 2012.

19. Vermeulen MJ, Guttmann A, Stukel TA, et al. Are reductions in emergency department length of stay associated with improvements in quality of care? A difference-in-differences analysis. BMJ Qual Saf. 2015.

20. Saad F, Finelli A, Dranitsaris G, et al. Does prolonging the time to prostate cancer surgery impact long-term cancer control: a systematic review of the literature. Can J Urol. 2006; 13(Suppl 3):16-24.

21. Tran K, Sandoval C, Rahal R, et al. Wait times for prostate cancer treatment and patient perceptions of care in Canada: a mixed-methods report. Current oncology (Toronto, Ont). 2015;22:361-4.

22. Snyder J, Johnston R, Crooks VA, Morgan J, Adams K. How medical tourism enables preferential access to care: four patterns from the Canadian context. Health Care Anal: HCA: J Health Philos Policy. 2016.

23. Metz LM, Greenfield J, Marrie RA, et al. Medical tourism for CCSVI procedures in people with multiple sclerosis: an observational study. Can $J$ Neurol Sci. 2016;43:360-7.

24. Loh CP. Trends and structural shifts in health tourism: evidence from seasonal time-series data on health-related travel spending by Canada during 1970-2010. Soc Sci Med. 2015;132:173-80.

25. Siddiqi A, Zuberi D, Nguyen $\mathbf{G C}$. The role of health insurance in explaining immigrant versus non-immigrant disparities in access to health care: comparing the United States to Canada. Soc Sci Med. 2009;69:1452-9.

26. Gorey KM. Breast cancer survival in Canada and the USA: meta-analytic evidence of a Canadian advantage in low-income areas. Int $\mathrm{J}$ Epidemiol. 2009;38:1543-51.

27. Valentine N, Verdes-Tennant E, Bonsel G. Health systems' responsiveness and reporting behaviour: Multilevel analysis of the influence of individual-level factors in 64 countries. Soc Sci Med. 2015; 138: 152-60.

28. Trinh HQ, Begun JW, Luke RD. Hospital service duplication: evidence on the medical arms race. Health Care Manag Rev. 2008;33:192-202.

29. Siddiqui ZK, Zuccarelli R, Durkin N, Wu AW, Brotman DJ. Changes in patient satisfaction related to hospital renovation: experience with a new clinical building. J Hosp Med. 2015;10:165-71.

30. Woolhandler S, Himmelstein DU. A national health program: northern light at the end of the tunnel. JAMA. 1989;262:2136-7.

31. Fooks C, Decter M. The transformation experience of the veterans health administration and its relevance to Canada. Healthc Pap. 2005;5:60-4.

32. Naylor CD. Health care in Canada: incrementalism under fiscal duress. Health Aff (Millwood). 1999; 18:9-26.

33. Sutherland JM, McGrail KM, Law MR, Barer ML, Crump RT. British Columbia hospitals: examination and assessment of payment reform (BCHeaPR). BMC Health Serv Res. 2011;11:150. 